\title{
СОВРЕМЕННЫЕ ПОДХОДЫ К НОРМИРОВАНИЮ СОДЕРЖАНИЯ ТЯЖЕЛЫХ МЕТАЛЛОВ В ПОЧВЕ
}

\author{
Васин Денис Викторович \\ кандидат географических наук, доцент \\ МГОУ (Московский государственный областной университет)
}

\begin{abstract}
Аннотация. В статье рассматриваются вопросы нормирования содержания тяжёлых металлов в почве. Приводятся показатели предельно - допустимых концентраций (ПДК), описывается предельное допустимое содержание подвижной формы тяжелых металлов, а также дается классификация биохимически активных элементов в кислых и сильно кислых почвах.

Abstract. The article deals with the issues of normalization of the content of heavy metals in the soil. The indicators of the maximum permissible concentration (MPC) are given, the maximum permissible content of the mobile form of heavy metals is described, and the classification of biochemically active elements in acidic and strongly acidic soils is given

Ключевые слова: нормирование, тяжелые металлы, кислые почвы, предельно - допустимые концентрации (ПДК), биохимически активные элементы, фоновые значения

Keywords: rationing, heavy metals, acidic soils, maximum permissible concentrations (MPC), biochemically active elements, background values
\end{abstract}

Определению «тяжелые металлы» соответствует достаточно большое количество элементов, однако соединения этих элементов далеко не равнозначны как загрязняющие вещества [1].

В процессе хозяйственной деятельности в почву поступает огромное количество веществ, геохимическая активность которых изменяется в зависимости от местных условий [2].

Нормирование содержания тяжелых металлов в почве является в настоящее время довольно сложной проблемой, так как невозможно полностью учесть все факторы изменяющейся природной среды. Изменение одних факторов неизменно приводит к изменению других. Например, при меняющихся агрохимических свойствах почвы (реакция среды, содержание гумуса, степень насыщенности основаниями, гранулометрический состав) увеличивается или уменьшается в несколько раз содержание тяжелых металлов в растениях. Нормирование тяжелых металлов в почвах необходимо для установления их фоновых значений и установление их предельно - допустимых концентраций (ПДК). Под ПДК тяжелых металлов следует понимать такую их концентрацию, которая при длительном действии на почву не вызывает каких-либо патологических изменений или аномалий в ходе биологических процессов, а также не приводит к накоплению токсических элементов в растениях и, следовательно, не может нарушить биологический оптимум для животных и человек[3]. В некоторых случаях за предельно - допустимую концентрацию принято самое высокое содержание металлов, наблюдаемое в обычных антропогенных почвах, в других - содержание, являющееся предельным по фитотоксичности. В большинстве случаев для тяжелых металлов предложены ПДК, превосходящие верхнюю норму в несколько раз (табл. 1). Существует несоответствие в ряде случаев между ПДК и фоновыми значениями, так как иногда фоновое содержание тяжелых металлов в почвах относительно незагрязненных территорий превышает величины ПДК.

В последнее время осуществляются попытки создать ПДК для всех почвенных типов различных климатических зон [4]. Для почв различных территорий необходимо рассчитать предельную величину нагрузок, обеспечивающее нормальное функционирование экосистем. Часто нормирование осуществляется для агрономических, санитарно -гигиенических и почвенно - экологических целей [5]

Таблица 1.

Предельно - допустимые концентрации (ПДК) химических веществ в почвах и допустимые уровни их содержания по показателям вредности, мг/кг

\begin{tabular}{|c|c|c|c|c|}
\hline \multirow{2}{*}{$\begin{array}{c}\text { Наименова- ние } \\
\text { веществ } \\
\end{array}$} & \multirow{2}{*}{$\begin{array}{c}\text { ПДК, мг/кг почвы, с учетом } \\
\text { фона }\end{array}$} & \multicolumn{3}{|c|}{ Показатели вредности } \\
\hline & & Транслокационный & Водный & Общесани- тарный \\
\hline \multicolumn{5}{|c|}{ Водорастворимые формы } \\
\hline Фтор & 10,0 & 10,0 & 10,0 & 25,0 \\
\hline \multicolumn{5}{|c|}{ Подвижные формы } \\
\hline Медь & 3,0 & 3,5 & 72,0 & 3,0 \\
\hline Никель & 4,0 & 6,7 & 14,0 & 4,0 \\
\hline Цинк & 23,0 & 23,0 & 200,0 & 37,0 \\
\hline Кобальт & 5,0 & 25,0 & $>1000$ & 5,0 \\
\hline Фтор & 2,8 & 2,8 & - & - \\
\hline Хром & 6,0 & - & - & 6,0 \\
\hline \multicolumn{5}{|c|}{ Валовое содержание } \\
\hline
\end{tabular}




\begin{tabular}{|c|c|c|c|c|}
\hline Сурьма & 4,5 & 4,5 & 4,5 & 50,0 \\
\hline Марганец & 1500 & 3500,0 & 1500,0 & 1500,0 \\
\hline Ванадий & 150 & 170,0 & 350,0 & 150,0 \\
\hline Свинец & 30,0 & 35,0 & 260,0 & 30,0 \\
\hline Мышьяк & 2,0 & 2,0 & 15,0 & 10,0 \\
\hline Ртуть* & 2,1 & 2,1 & 33,3 & 5,0 \\
\hline Свинец + ртуть & $20+1$ & $20+1$ & $30+2$ & $30+2$ \\
\hline Медь** & 55 & - & - & - \\
\hline Никель** & 85 & - & - & - \\
\hline Цинк** & 100 & - & - & - \\
\hline
\end{tabular}

* - Миграционный показатель вредности ртути в атмосфере $-2,5$

** - Валовое содержание ориентировочное.

Из таблицы видно, что наиболее разработаны нормативы для валовых форм, которые характеризуют общую загрязненность почвы, а доступные для растений подвижные формы изучены недостаточно. ПДК подвижных форм некоторых наиболее распространенных и токсичных тяжелых металлов представлены в табл.2.

Таблица 2.

Предельно - допустимое содержание подвижной формы тяжелых металлов в почве, мг/кг экстрагент 1н. НСI [6]

\begin{tabular}{|c|c|c|c|c|c|}
\hline Элемент & Содержание & Элемент & Содержание & Элемент & Содержание \\
\hline $\mathrm{Hg}$ & 0,1 & $\mathrm{Sb}$ & 15 & $\mathrm{~Pb}$ & 60 \\
\hline $\mathrm{Cd}$ & 1,0 & $\mathrm{As}$ & 15 & $\mathrm{Zn}$ & 60 \\
\hline $\mathrm{Co}$ & 12 & $\mathrm{Ni}$ & 36 & $\mathrm{~V}$ & 80 \\
\hline $\mathrm{Cr}$ & 15 & $\mathrm{Cu}$ & 50 & $\mathrm{Mn}$ & 600 \\
\hline
\end{tabular}

В условиях преобладания кислых почв с промывным режимом в Средней полосе России изучение подвижности активных химических элементов приобретает первостепенное значение. Степень подвижности биохимически активных элементов представлена в таблице 3.

Таблица 3.

Подвижность биохимически активных элементов в кислых и сильно кислых почвах

\begin{tabular}{|c|c|c|}
\hline Степень подвижности элементов & Аэрируемые почвы & Оглеенные почвы \\
\hline Неподвижные & Mо & $\mathrm{As}, \mathrm{U}, \mathrm{Mo}, \mathrm{S}, \mathrm{Se}$ \\
\hline Умеренно подвижные & $\mathrm{Pb}, \mathrm{As}, \mathrm{Se}, \mathrm{Cr}, \mathrm{Ni}, \mathrm{Co}, \mathrm{U}$ & $\mathrm{Pb}, \mathrm{Ni}, \mathrm{Cr}, \mathrm{Co}, \mathrm{Cu}, \mathrm{Zn}$ \\
\hline Легко подвижные & $\mathrm{Cd}, \mathrm{Hg}, \mathrm{Cu}, \mathrm{Zn}, \mathrm{Sr}, \mathrm{Ba}, \mathrm{S}$ & $\mathrm{Sr}, \mathrm{Ba}, \mathrm{Ag}$ \\
\hline
\end{tabular}

Медики - гигиенисты часто оценивают ПДК по трем показателям: транслокационному (переход тяжелых металлов из почвы в растения через корни), водному (переход в воду) и общесанитарному (влияние на почвенную биоту, на самоочищение, на ферментативную активность и азотфиксацию). Отмечается, что ПДК тяжелых металлов в почвах разных стран рассматриваются как непостоянные относительные величины, которые зависят от почвенно - экологических условий конкретных регионов.

В таблице 4 представлены ПДК тяжелых металлов в почвах по данным разных авторов. В последнее время ставятся вопросы о целесообразности применения ПДК. Более того, некоторые исследователи даже настаивают на отмене данного показателя [7], так как ПДК некоторых веществ оказываются ниже их фонового содержания в почвах.

Таблица 4.

Предельно - допустимые концентрации (ПДК) тяжелых металлов

в почвах по данным разных авторов, мг/кг

\begin{tabular}{|c|c|c|c|}
\hline Элемент & ПДК $[8]$ & ПДК $[9]($ Kloke, 1980) & ПДК [10] (Timmermann, 1987) \\
\hline $\mathrm{As}$ & 50 & 20 & - \\
\hline $\mathrm{Cd}$ & 5 & 3 & 2 \\
\hline $\mathrm{Co}$ & 50 & 50 & - \\
\hline $\mathrm{Cr}$ & 100 & 100 & 60 \\
\hline $\mathrm{Cu}$ & 100 & 100 & - \\
\hline $\mathrm{Hg}$ & 5 & 2 & - \\
\hline $\mathrm{Mn}$ & - & - & - \\
\hline $\mathrm{Mo}$ & 10 & 5 & 50 \\
\hline $\mathrm{Ni}$ & 100 & 50 & \\
\hline
\end{tabular}




\begin{tabular}{|c|c|c|c|}
\hline $\mathrm{Pb}$ & 100 & 100 & - \\
\hline $\mathrm{Se}$ & 10 & 10 & - \\
\hline $\mathrm{Ti}$ & - & 5000 & - \\
\hline $\mathrm{V}$ & - & 100 & $150-200$ \\
\hline $\mathrm{Zn}$ & 300 & 300 & - \\
\hline $\mathrm{Sr}$ & - & 300 & \\
\hline
\end{tabular}

ПДК установлены для более 1000 химических веществ в воде, более 250 в атмосферном воздухе и более 30 в почвах, однако нормативы ПДК часто не отражают настоящей роли элементов в различных экосистемах и являются недостаточно обоснованными. Так же недостаточно изученным является влияние на почвенную микробиоту. Тем не менее эти факторы не должны исключать важное методологическое значения ПДК как главного критерия, который необходим для оценки качества окружающей среды. Разработанные ориентировочно - допустимые концентрации (ОДК) для валового содержания тяжелых металлов и мышьяка позволяют получить более полную характеристику о загрязнении почвы тяжелыми металлами, так как учитывают уровень реакции среды и гранулометрический состав почв.

Загрязнители можно разделить на четыре группы: почвохимически активные, биохимически активные, а также сочетающие в себе признаки обеих групп и индифферентные. В первую группу включены вещества (оксиды щелочноземельных катионов, минеральные кислоты), воздействующие на щелочно - кислотные окислительно - восстановительные условия, меняющие педохимическую обстановку, морфологию почвенного профиля, во вторую - вещества, активно воздействующие на биоту почв. Это - тяжелые металлы, радиоактивные вещества. В третью входят вещества, которые одновременно относятся к почвохимически активным, которые также требуют повышенного внимания. Это тяжелые металлы в высоких концентрациях, способные к гидролизу, отрицательно воздействующие не только на биоту, но и на физико-химические свойства почв, причем это воздействие достаточно длительное и может привести к серьезным последствиям. К четвертой группе отнесены оксиды кремния, железа, глинистые минералы и другие и другие, не оказывающие существенного влияния на почвенно - растительный покров. Нормирование содержание загрязнителей в почвенно - растительном покрове должно учитывать ситуацию, когда скорость поступления загрязнителей значительно выше скорости их почвенной трансформации. Такая ситуация складывается в локальной зоне загрязнения и может приводить к необратимым последствиям.

\section{Список литературы}

асин Д.В. Содержание тяжелых металлов в почвах разных агроклиматических зон Ульяновской области. Сравнительная характеристика распределения тяжелых металлов в почвах Ульяновской области и в соседних регионах (на примере Самарской области). Современные проблемы науки и образования 2013, №1, С. 441

асин Д.В. Современное геоэкологическое состояние почв Московской области. В сборнике: Добродеевские чтения - 2017, стр.21-23

Ильин В.Б. Тяжелые металлы в системе почва-растение. Новосибирск: Наука, 1991. 151 с.

орчарук Е. И., Сидоренко Г. И. Гигиеническое нормирование химических веществ в почве, М.: Медицина, 1986, $320 \mathrm{c}$.

зраэль Ю.А. Экология и контроль состояния природной среды и пути их решения. Л.: Гидрометеоиздат, 1984.560 с улджиян X., Карвета С., Фацек 3., Тяжелые металлы в почвах и растениях //Экологическая кооперация. Братислава, 1988. Вып. 1, с 5-24

обровольский В.В. Ландшафтно - геохимические критерии оценки загрязнения почвенного покрова тяжелыми металлами //Почвоведение, 1999, №5, с. 639-645

эуце К., Кырстя С. Борьба с загрязнением почвы. М.: Агропромиздат,1986, 221с.

9. Kloke A. Orientierungsdaten ftir tolerierbare Gesamtgehalte einiger Elemente in Kulturbuden // Mitteilungen VDLUFA. 1980. H.2. S.32-38.

10. Timmermann F., Scott W., Nutzen und Risigen der Landwirschaftlicher Verwetung von Klarschlammer und Siedlungsko mposten // VDLUFA -Schriftreihe/ kongressband, 1987, 24 s. 